\title{
Spiralling up Professionalism - An integrated model for Higher Education
}

\author{
A. Davies* ${ }^{*}$ H. Lynch ${ }^{*}$ \\ *School of Policing, Charles Sturt University
}

\begin{abstract}
Globally the higher education community continues to explore curriculum delivery models which connect theory to practice to support the transfer of learning from the classroom to operational practice. Police recruit education is no exception and utilises a myriad of curriculum design and delivery models. Since 1998 the New South Wales Police Force in Australia has worked in partnership with Charles Sturt University on a degree based recruit education program. Continuous improvement and evaluation of the program has resulted in the implementation of an innovative curriculum design and delivery approach which challenges the traditional university subject learning process. This paper discusses the innovative model which is built on (1) the concept of situated learning and (2) the constructive alignment approach to teaching and learning. The learning delivery design is supported by a unique distributed content technology environment. The model and the initial results of its evaluation are presented. The initial findings suggest an increase in the level of preparedness of the student recruit for operational practice. The approach offers a contribution to higher education course development in which a central tenant is establishing a seamless segue from student to professional.
\end{abstract}

Keywords: policing; integrated curriculum; integrated assessment; distributed environment

\section{Introduction}

Whilst there is a sustained debate surrounding situating police recruit education in the higher education paradigm (see Lee \& Punch, 2004; Cox,2001; Rydberg \& Terrill, 2010) the NSW Wood Royal Commission (1997) recommended the NSW Police Force (NSWPF) partner with a university to promote academic rigor and professionalism in police recruit education. Charles Sturt University has partnered with the NSWPF since 1998 in delivering the NSWPF recruit education program through the study of initially, a Diploma in Policing Practice and since 2003 the Associate Degree in Policing Practice (ADPP). In the traditional curriculum design of university studies, the learning in these two study programs was centred on the study of individual subjects which collectively contributed to the awarding of the Diploma/Associate Degree. In parallel, students completed physical skill training relevant to operational policing e.g. officer safety skills, pursuit driving skills and personal physical fitness skills. The learning objectives of the curriculum are to prepare the policing student for their operational duties. Further the studies are designed to provide academic rigor to the student learning through underpinning the curriculum content with study of the theories which provide the guiding principles for policing in a western democratic society. In practical terms the study of policing practice through an academically founded program provides insight and knowledge as to 'why police do what they do'. A catalyst for rethinking the design and delivery of the ADPP centred on the analysis of field based evaluations conducted on a four yearly basis. The analyses consistently identified the curriculum developed the students' knowledge of theory however there remained opportunity to more adequately connect theory to practice for the policing students to support the quantum shift from student to operational police officer.

\section{Historical model of learning delivery}

Prior to January 2014 students studying the ADPP were enrolled, studied and assessed in individual subjects e.g. Communications in Policing, Police Crime and Society, Policing and Road Safety. The enrolment and progression pattern for the ADPP pre and post 2014 is similar in design to align with university enrolment policies and the NSWPF optional study pathways 
requirements. Students are enrolled in individual subjects which collectively comprise a degree program. The post January 2014 ADPP course as depicted in Figure 1 indicates the flexible nature of the program enabling full-time on campus or distance education study pathways for the commencing session of the program. The study program presented in Table 1 portrays on the surface, the hallmarks of traditional university study programs: retention of a collective of subjects comprising a course of study. Rethinking the delivery design of the program to enhance student learning defaulted therefore to below the subject and course surface.

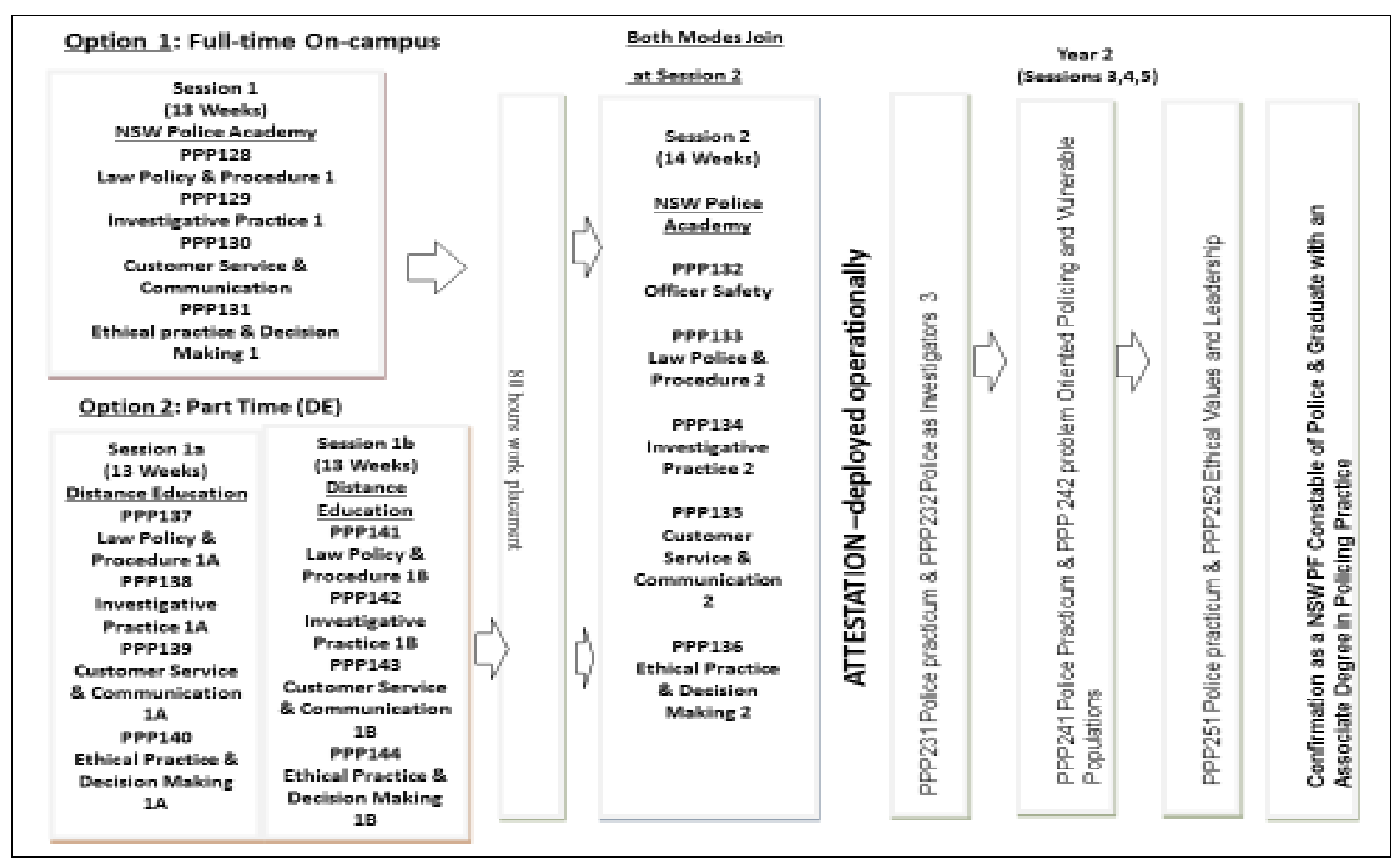

Figure 1 Associate Degree in Policing integrated curriculum study program

The key objective in the redesign of the ADPP curriculum and assessment was to draw the operational field into the classroom offering increased contextualisation of curriculum content.

\section{Integrated curriculum content and assessment}

Integrated curriculum as a design concept for learning has produced a myriad of literature which examines the advantages and disadvantages from multiple perspectives. It is not a new concept, however, as suggested by Zhou and Kim (2010, p. 123) a consistent universally accepted definition remains unresolved:

...debate has not yet resulted in an agreement over the meaning and the appropriate practice of curriculum integration”

Gresnight et.al. (2014) provided a comprehensive insight into the historical debate in referring to the work of Beane (1997), Drake $(2000,2007)$ and Fogarty (2009). The implication of the continued debate suggests the concept of an integrated curriculum therefore has no singular stand-alone role model, rather it is adapted and moulded by educators to meet specific overarching parameters (social, political, environmental, economic and legal) relevant to the education institution. The development of an integrated curriculum and assessment model for the ADPP is an example of such flexible adaptation of the concept of integration. The ADPP model reflects a combination of the three categories of integration as proffered by the early 
work of Drake (2000) in this field and includes: content focus, skill focus and the combination of life-context focus.

The revised ADPP curriculum is premised on mirroring the field based duties of police officers, scaffolding the learning on core operational tasks. Modules of delivery have been designed which draw learning content from each of the individual subjects to address the policing responsibilities and skills attached to the focus of the module. Figure 2 offers graphic representation of the relationship between course, subject, module and learning environment for the commencing Session One of the program. A similar design principle underpins Session Two of the program. Session Two has no distance education study option, all students are full time on campus. Sessions Three, Four and Five are studied during the first 12 months of a probationary constable's (PC) operational deployment. Each field based session comprises study of one academic subject via distance education and one practicum subject related to field based activities.

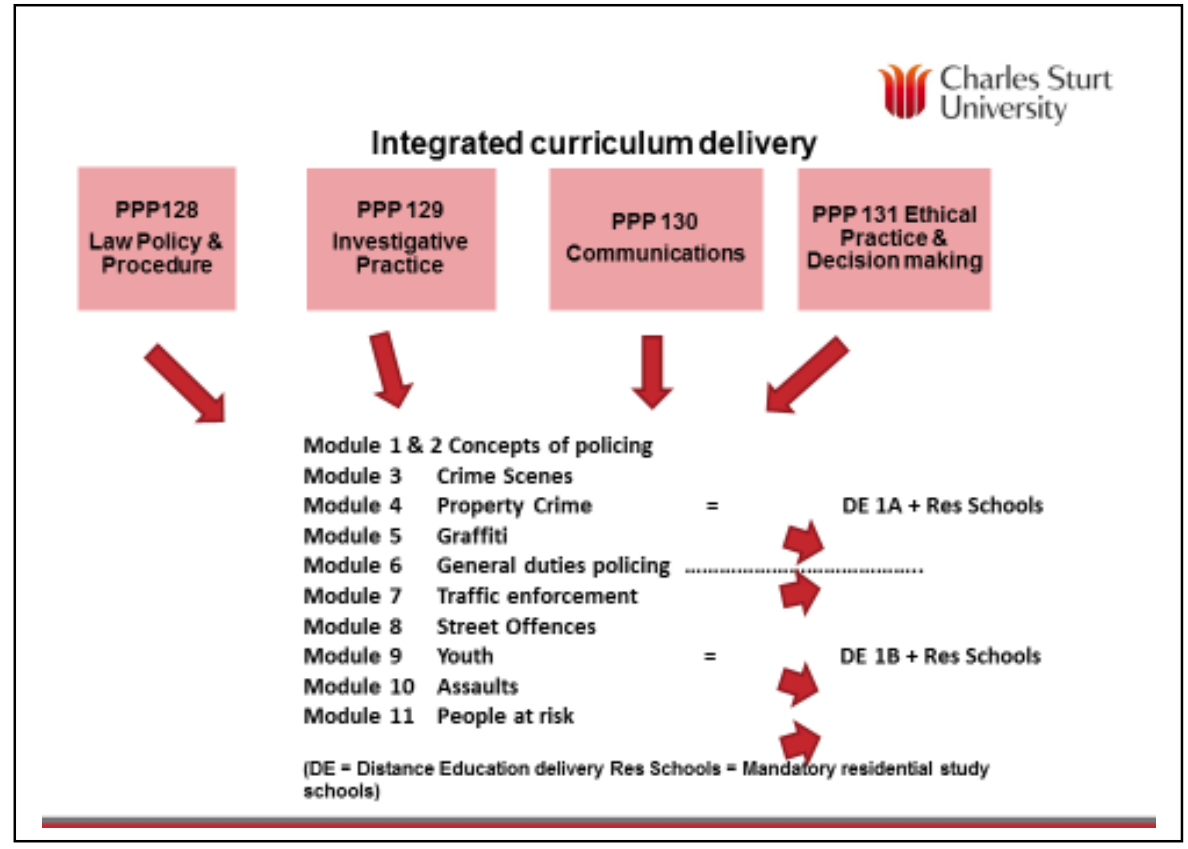

Figure 2 ADPP integrated curriculum delivery model Session 1

An important consideration underpinning this integrated learning design is the inclusion of learning experiences which afford the student opportunity to apply the knowledge and skills they acquire on a continual basis throughout the sessions of study. Contextualising the learning content and experience is a pivotal design characteristic which aids students' recognition and acknowledgement of the relevance of acquiring the knowledge and skills presented within the ADPP curriculum. Not only is contextualised practical application built into the module lessons in the classroom, this learning approach is extended through student participation in weekly simulated policing exercises within a purpose built scenario village at the Academy. Guiding principles which have contributed to the design of module lessons have been drawn from the concepts of situated learning (Collins, 1999) and the work of Herrington, Herrington, Oliver and Reeves in design constructs for authentic learning and assessment (see Herrington \& Herrington, 1998, 2006; Herrington \& Oliver, 1995, Herrington, Reeves \& Oliver, 2007; Herrington, Oliver \& Reeves, 2003). Herrington heralded the complexities faced by educators in seeking to align university teaching with contextualisation of learning in commenting:

...The challenge they have faced is to align university teaching and learning more substantially with the way learning is achieved in real-life settings, and base instructional methods on more authentic approaches such as situated learning (2006, p. 3). 
In parallel with embedding the principles of authentic and situated learning, the integrated curriculum has followed a constructive alignment approach. The seminal work of Biggs in the field of constructive alignment principles - where the learners' activities are pivotal in creating meaning (Biggs, 1996, p.347) has underpinned the design framework for the integrated curriculum. The alignment of learning objectives for the whole of course with learning objectives for individual lessons and assessment followed by scaffolding these to learning exercises and content within individual lessons enables the continual and transparent monitoring of adherence to the underpinning course design principles.

The integrated ADPP curriculum accommodates the traditional university method of awarding subject credits whilst maintaining an integrated assessment process. Figure 3 presents an example of the integrated assessment design.

\begin{tabular}{|c|c|c|c|c|}
\hline Subject & $\begin{array}{l}\text { Credit } \\
\text { Points }\end{array}$ & $\begin{array}{l}\text { Assessment Item } 2 \\
\text { Theory Exam Part a, b, c, d }\end{array}$ & Assessment Item & $\begin{array}{l}\text { Assessment } \\
\text { Item }\end{array}$ \\
\hline \multirow[t]{2}{*}{$\begin{array}{l}\text { PPP128 } \\
\text { Law Policy and } \\
\text { Procedure } \\
\end{array}$} & 16 & $\begin{array}{l}\text { 2A \& } 2 \text { B Exam m/c questions } \\
\text { 2C \& 2D Exam m/c questions } \\
\text { Combined Pass mark 70\% }\end{array}$ & $\begin{array}{l}\text { Item } 6 \text { Law Exam } \\
\text { Pass mark 50\% }\end{array}$ & $\begin{array}{l}\text { Item } 3 \\
\text { Police Practical } \\
\text { Graded SY/US }\end{array}$ \\
\hline & & Combined weighting of 50\% & $50 \%$ & SY/US \\
\hline \multirow[t]{2}{*}{$\begin{array}{l}\text { PPP129 } \\
\text { Investigative } \\
\text { Practice } 1\end{array}$} & 8 & $\begin{array}{l}\text { 2A \& } 2 \text { B Exam m/c questions } \\
\text { 2C \& 2D Exam m/c questions } \\
\text { Combined Pass mark 70\% }\end{array}$ & $\begin{array}{l}\text { Item } 5 \\
\text { Investigations } \\
\text { Assign/Exam } \\
\text { Pass mark 50\% }\end{array}$ & $\begin{array}{l}\text { Item } 3 \\
\text { Police Practical }\end{array}$ \\
\hline & & Combined weighting of $50 \%$ & $50 \%$ & SY/US \\
\hline \multirow[t]{2}{*}{$\begin{array}{l}\text { PPP130 } \\
\text { Customer Service } \\
\text { Communication } \\
1 \\
\end{array}$} & 8 & $\begin{array}{l}\text { 2A \& } 2 \text { B Exam m/c questions } \\
\text { 2C \& 2D Exam m/c questions } \\
\text { Combined mark 70\% }\end{array}$ & $\begin{array}{l}\text { Item } 1 \\
\text { Communications } \\
\text { Exam ( CAPS) } \\
\text { Pass mark 50\% } \\
\end{array}$ & $\begin{array}{l}\text { Item } 3 \\
\text { Police Practical }\end{array}$ \\
\hline & & Combined weighting of $50 \%$ & $50 \%$ & SY/US \\
\hline \multirow[t]{2}{*}{$\begin{array}{l}\text { PPP131 } \\
\text { Ethical Practice } \\
\text { Decision Making } \\
1\end{array}$} & 8 & $\begin{array}{l}\text { 2A \& } 2 \text { B Exam m/c questions } \\
\text { 2C \& 2D Exam m/c questions } \\
\text { Combined Pass mark 70\% }\end{array}$ & $\begin{array}{l}\text { Item } 4 \\
\text { Ethics (Essay) } \\
\text { Assignment } \\
\text { Pass mark 50\% }\end{array}$ & $\begin{array}{l}\text { Item } 3 \\
\text { Police Practical }\end{array}$ \\
\hline & & Combined weighting of $50 \%$ & $50 \%$ & SY/US \\
\hline
\end{tabular}

Figure 3 ADPP Session 1 Integrated Assessment model

The pivotal assessment item which provides for an integrated approach to assessing student learning is a theory exam consisting of multiple choice questions and short/extended answer responses. The theory exam is based on one or several scenarios to which blocks of questions from each individual subject area are applied. The performance in each subject block contributes to the overall student mark for the subject. Additional assessment items for each individual subject are included allowing for assessment of student knowledge and skills from multiple perspectives. The assessment process requires students to undertake a simulated policing response exercise, their performance is marked against learning objectives for each individual subject category e.g. demonstration of communication skills is awarded a satisfactory or unsatisfactory mark and attributed to the overall Communications in Policing subject mark awarded. The integrated assessment design is cognisant of the necessity in terms of student progression and transcript of studies to identify in each subject area where a student passes or fails. One of the products and processes which has (1) supported the integrated approach for the full time and distanced education learning and (2) allowed for monitoring of the contextualisation of learning content and creation of authentic contextualised learning experiences is the introduction of a distributed content environment (DCE). 


\section{Learning materials and a distributed content and environment (DCE)}

The Distributed Content Environment (DCE) was specifically designed to facilitate the development, reuse, management and distribution of curriculum and learning resources. The DCE makes learning materials available to F2F students, teaching staff, the classroom and distance learners online in a range of highly accessible digital content formats (Lynch, 2015). In a learning environment driven by authentic and situated learning principles real-time, any place access to resources that support contextualised learning is pivotal. With a DCE students have instant access to their audio-visual and textual resources inside and outside of the classroom for lesson preparation, in class activities, field activities, and lesson and learning review. For ADPP students the DCE provides a Study Guide in .epub and markable .pdf format for mobile devices or laptops (which draws resources via weblink from websites or digital object repository sites wrapping them in relevant instructional text). The DCE becomes a conduit through which student resources can be presented, watched, heard or enacted at any time.

In parallel, teaching staff are provided identical flexibility of access to teaching resources, which are a repackaged version of the student accessible content, with additional instructional guidance. The facilitator package allows for the presentation of selected digital resources via the university's online learning environment and classroom display technologies. A major benefit realised is the facilitation of the continuous improvement of the curriculum by providing an environment in which content is readily and seamlessly updated and distributed. This is an important consideration in policing studies which requires accommodation of continuous changes to legislation, police policies and practices. As this innovative approach to the development and distribution of learning materials and a holistic learning environment is a 'new system' the full potential of the DCE has yet to be explored. However, in the evaluation project undertaken in March 2015, students provided feedback as to their experience with the online environment and its relationship to supporting their field based activities.

\section{Evaluation}

It was to be expected as with new courses, there would need to be revision and amendment, the reality being a lesson written on paper can 'look' quite different when experienced in the classroom. A formal evaluation study was conducted in March 2015. The timing of the evaluation was premised on allowing a 'settling in' of the learning delivery design for students and teachers. Importantly, this time frame offered opportunity for the PCs to respond from a position of 6-8 weeks operational experience.

\section{Method}

A case study approach was undertaken in the preliminary formal evaluation research project. The project objectives aligned with the case study characteristics advocated by Stake (2005) of issue choice; triangulation; experiential knowledge; contexts and activities. There is a sound body of literature devoted to reasoning for situating evaluation of education initiatives within a case study frame work (see: Simons 2009, Merriam 2009; Burns, 2000.) A qualitative data collection approach was employed aligning with the rationale proffered by the seminal work in this field of Bryman (1988); Miles and Huberman (1994) and Patton (2002). Allowing the PCs and their field based trainers and supervisors to give voice to their observations had the potential to offer rich insight into the relationship between the curriculum and the field of operational practice. Worthy of note is the preliminary nature of this evaluation project as the first phase of future broader evaluative studies of the ADPP program. 
The complete cohort of 300 PCs who commenced operationally in January 2015 (2 ${ }^{\text {nd }}$ cohort to graduate through the integrated curriculum) were invited to complete an on-line survey comprised of short answer questions. A total of 153 participants completed the survey. In addition total of 15 participants were invited to participate in a short telephone interview. The selection of interviewees was based on capturing a range representative of the cohort by age, gender, and location of the NSW Police Station to which they were deployed (country, metropolitan and coastal). The survey and semi-structured interview questions focused on: (1) level of preparedness for operational policing; (2) content/experiences within the Academy based studies which they consider of most valuable for their operational practice; (3) areas of learning they consider would be helpful if studied prior to deployment; and (4) the value of the technology employed in the delivery of the curriculum as it relates to their operational practice. The PCs are supervised in the first 6 weeks of their field based operation by Field Training Officers (FTO) and Educational Development Officers (EDO). These officers have experience with training and supervising PCs who have studied under the previous non-integrated curriculum and the current integrated curriculum. This experience situates them appropriately to offer insight into variances they have observed with graduates of the two programs. A total of 15 EDO/FTOs were interviewed, their selection premised on gender and NSW Police Station location (country, metropolitan and coastal). The evaluation study embraced wide ranging issues, however for this paper it is the data which informs on the relationship between the integrated curriculum and its influence on the field based preparedness of the recruit officers which is included in the following section.

\section{Results and Discussion}

A note of caution is offered in relation to the following data it is preliminary in nature and does not at this stage explore potential influences other than the curriculum on the level of preparedness of the PCs. As presented in Table 1, the data reported $93.62 \%$ of the PCs feeling confident in their level of preparedness for operational practice. Whilst not detracting from the encouraging positive response and reflection on the curriculum, the PCs also offered suggestions for curriculum inclusions which may further build their level of preparedness. The level of confidence indicated in Table 1 is supported by the observations from the EDO/FTO interviews.

Table 1 Confidence in level of preparedness reported by PCs

\begin{tabular}{|c|c|c|c|c|}
\hline \multicolumn{4}{|l|}{$\begin{array}{l}\text { Question 4: How confident did you feel in your level of preparedness for operational duty when you attested } \\
\text { from the Academy? Responses=153 (\% calculated on response identifying level } n=141 \text { ) }\end{array}$} \\
\hline $\begin{array}{l}\text { Not very; less } \\
\text { than confident }\end{array}$ & $\begin{array}{l}\text { Somewhat; } \\
\text { slightly }\end{array}$ & $\begin{array}{l}\text { Confident; fairly; 50\% } \\
\text { moderate; good }\end{array}$ & $\begin{array}{l}\text { Solid; very } \\
\text { confident; 7/10 }\end{array}$ & $\begin{array}{l}\text { Confidence level not } \\
\text { indicated }\end{array}$ \\
\hline 9 & 18 & 96 & 18 & 12 \\
\hline $6.38 \%$ & $12.765 \%$ & $68.08 \%$ & $12.765 \%$ & \\
\hline
\end{tabular}

The general response from the EDO/FTOs was that the PCs displayed a broader confidence and awareness of their role and the job and more faith in their abilities. Table 2 presents examples of the EDO/FTO responses to interview Question 3. 
Table 2 EDO/FTO Observations of Level of Preparedness of PCs

\begin{tabular}{|c|c|}
\hline $\begin{array}{l}\text { EDO (Coastal Local } \\
\text { Area Command) }\end{array}$ & $\begin{array}{l}\text { The PCs we have at the moment are on the ball, in relation to level of preparedness } \\
\text { it is like they have been here before and doing it the } 2^{\text {nd }} \text { day on the job }\end{array}$ \\
\hline $\begin{array}{l}\text { EDO (Metropolitan } \\
\text { Local Area } \\
\text { Command) }\end{array}$ & $\begin{array}{l}\text { I think particularly this group, they seem to be more switched on in so far as a } \\
\text { holistic approach. They seem to have a broader confidence about them and } \\
\text { awareness, more faith in their abilities. }\end{array}$ \\
\hline $\begin{array}{l}\text { EDO ( Country Local } \\
\text { Area Command) }\end{array}$ & $\begin{array}{l}\text { I have been an EDO for } 8 \text { years... the quality of work seems a lot more switched } \\
\text { on...they seem like they have been in the job before. I used to get 100's of } \\
\text { questions, but it all just seems to happen naturally with this group. }\end{array}$ \\
\hline
\end{tabular}

An interesting trend emerged from the data collected which focussed on the relationship between embedding a distributed content environment with all learning materials in a digital format and the useability and connection for the PCs. The 15 PCs interviewed agreed that having to work with digital resources in the Academy studies developed their confidence and capability with technology for policing. The interesting trend which emerged during interview was that the PCs indicated they are returning to their digital resources utilised during studies at the Academy to now use as reference sources in their field based operations. This trend was universal across the 15 PCs interviewed. The following comment from Participant 12 is indicative of this trend:

...they are really valuable, I find if I have a bit of time at work I jump on line and recap

some of the information. Having it available 24/7 is really helpful;

and Participant 10:

...The materials are always there for you, sometimes I look at the Session One and Two material, I attend a lot of traffic issues so I went back to look at the traffic material on line. I also look up everyday things like move along directions.

The data offered here is a snapshot of the overall data collected for the project, this data is that which is specifically relevant to providing initial understanding if the curriculum design approach is heading in the right direction.

\section{Conclusion}

The innovative design approach for the ADPP has not been without challenges in preparation of the course material and transitioning both teaching staff and students to a 'new way of thinking' about learning. Whilst the early indicators offer evidenced based validation and support for this innovative approach to higher education for police recruits, it offers also a model for consideration by educators in pursuit of the nexus which connects theory with practice in a wide range of professions.

\section{References}

Beane, J.A. (1997). Curriculum integration: designing the core of democratic education. New York, NY: Teachers College Press.

Biggs, J. (1996). Enhancing teaching through constructive alignment. Higher Education, 32, 347-364.

Biggs, J. (1999). Teaching for Quality Learning at University, Buckingham, UK: SRHE and Open University Press.

Bryman, A. (1988). Quantity and quality in social research. London, England: Unwin Hyman.

Burns, R. B. (2000). Introduction to research methods (4th ed.). Sydney, Australia: Pearson Education Australia. 
Collins, A. (1988). Cognitive apprenticeship and instructional technology (Technical Report 6899). Cambridge, MA: BBN Labs Inc.

Cox, D. (2001). Educating police for uncertain times: The Australian experience and the case for a 'normative' approach. Journal of Policing, Intelligence and Counter Terrorism. 6(1), 3-22.

Drake, S. (2000) .Integrated curriculum: A chapter of the curriculum handbook. Alexandria, VA: Association of Supervision and Curriculum Development.

Drake, S. (2007). Creating standards-based integrated curriculum: aligning curriculum, content, assessment and instruction. ( $2^{\text {nd }}$ ed.). Thousand Oaks, CA: Corwin Press.

Fogarty, R. (2009). How to integrate the curricula. ( $3^{\text {rd }}$ ed.). Thousand Oaks, CA: Corwin Press.

Gresnight, R., Taconis, R., van keulen, H., Gravemeijer, K. \& Baartman, L. (2014). Promoting science and technology in primary education: a review of integrated curricula. Studies in Science Education. 50(1), 47-84. DOI: 101080/3057267.2013.877694

Herrington, J., \& Herrington, A. (1998). Authentic assessment and multimedia: How university students respond to a model of authentic assessment. Higher Education Research \& Development, 17(3), 305-322.

Herrington, J., \& Herrington, A.(2006). Authentic learning environments in Higher Education. Hershey, PA: Idea Group, Inc.

Herrington, J., Oliver, R., \& Reeves, T. C. (2003). Patterns of engagement in authentic online learning environments. Australian Journal of Technology, 19(1), 59-71.

Herrington, J., Reeves, T. C., \& Oliver, R. (2007). Immersive learning technologies: Realism and online authentic learning. Computing in Higher Education, 19(1), 80-99.

Lynch, H. (2015). The Distributed Content Environment. Retrieved from https://slidebean.com/p/TSo6f9t16V/The-Distributed-Content-Environment

Lee, M. \& Punch, M. (2004) Policing by degrees: Police officers' experience of university education. Policing and Society: An International Journal of Research and Policy, 14(3), 233-249.

Merriam, S. B. (2009). Qualitative research: A guide to design and implementation. San Francisco, CA: Jossey-Bass.

Miles, M. B., \& Huberman, M. A. (1994). Qualitative data analysis:An expanded sourcebook (2nd ed.). Thousand Oaks, CA: Sage.

New South Wales. Royal Commission into the New South Wales Police Service \& Wood, J. R. T. (James Roland T.) (1997). Final report. Royal Commission into the New South Wales Police Service, Sydney, N.S.W.

Patton, M. J. (2002). Qualitative research and evaluation methods (3rd ed.). Thousand Oaks, CA: Sage.

Reeves, T.C., Herrington, J., \& Oliver, R. (2002). Authentic activities and online learning. In A. Goody, J. Herrington \& M. Northcote (Eds), Quality conversations: Research and Development in Higher Education, Volume 25, (pp. 562-567). Jamison, ACT: HERDSA. http://www.ecu.edu.au/conferences/herdsa/papers/ref/pdf/Reeves.pdf

Rydber, J. \& Terrill, W. (2010). The effect of higher education on police behaviour. Police Quarterly, 13, 92-120.

Simons, H. (2009). Case study research in practice. London, England: Sage.

Zhou, G. \& Kim, J. (2010). Impact of an integrated methods course on pre-service teachers' perspectives of curriculum integration and faculty instructors' professional growth. Canadian Journal of Science, Mathematics and technology Education. 10(2), 123-138. 